\title{
Quality assessment in cardiac surgery: Measuring accurately, fairly, and easily, focusing on what can be changed
}

\author{
Oz M. Shapira, MD
}

See related article on pages 3076-81.

Treatment options for patients with cardiovascular disorders have expanded in the past decades to include new therapeutic agents and novel interventional techniques and technologies. In parallel, it has become clear that performance measurement is an essential component of this evolution to comply with the 4 principles of biomedical ethics. ${ }^{1}$ Thus the full disclosure of both individual caregiver and institutional performance is necessary to respect the patient's autonomy and provide the patient with the opportunity to make intelligent decisions voluntarily about the proposed therapeutic intervention, forming the basis for true "informed consent." Performance measurement is also mandatory to comply with the second and third ethical principles of nonmaleficence and beneficence-primum non nocere (first do no harm), affirming the need for medical competence and the ultimate duty of the health care provider to benefit the patient by delivering a high-quality care. ${ }^{1}$ Finally, to comply with the principle of justice, in an era of exponentially rising health care costs, performance measurement has become an essential component of procedural cost-effectiveness assessment to allow a fair distribution of health care resources to all members of the society.

Cardiac surgeons were among the first to embrace these principles, and for more than 2 decades they have collected data and developed metrics to measure performance and quality of care. Notable examples include the American Society of Thoracic Surgeons Database (STSDB), the European euroSCORE system, and other national registries. ${ }^{2}$ During this period, it became clear that a single measure, such as procedural mortality, is insufficient. Any comparison of performance of cardiac surgery programs that is based solely on a single or even several outcome measures is limited by low event rate (coronary artery bypass grafting mortality is in the range of $1.5 \%$ ), necessitating a high

From the Department of Cardiothoracic Surgery, Hadassah Hebrew University Medical Center, Jerusalem, Israel.

Disclosures: Author has nothing to disclose with regard to commercial support.

Received for publication Sept 29, 2014; accepted for publication Oct 1, 2014

Address for reprints: Oz M. Shapira, MD, Department of Cardiothoracic Surgery, Hadassah, Hebrew University Medical Center, POB 12000, EinKerem, Jerusalem 91120, Israel (E-mail: ozshapira@hadassah.org.il).

J Thorac Cardiovasc Surg 2014;148:3082-3

$0022-5223 / \$ 36.00$

Copyright (C) 2014 by The American Association for Thoracic Surgery

http://dx.doi.org/10.1016/j.jtcvs.2014.10.011 volume of cases to achieve a meaningful statistical analysis. In addition, many independent determinants of outcome are not modifiable (eg, age, sex, and preexisting morbidity such as diabetes). Thus a comprehensive set of metrics to assess the 3 aspects health care delivery-structure, process, and outcomes-is required to quantify accurately and reliably an abstract entity such as quality of care. ${ }^{3}$ Furthermore, risk adjustment of procedural outcomes is a prerequisite to allow a fair comparison among individual surgeons and institutions and to avoid aversion of high-risk cases. The STSDB algorithm for assessment of quality of care for patients undergoing coronary artery bypass grafting integrated these concept and includes the use of internal thoracic artery and perioperative medications (process metrics) and riskadjusted mortality and specific complications. ${ }^{2}$

In their article in this issue of the Journal, Coulson and colleagues ${ }^{4}$ have assessed the validity of a novel measure of quality after cardiac surgery-the ARCTIC index-in 16,687 patients undergoing coronary artery bypass grafting or valve surgery. The ARCTIC index was calculated as the difference between the predicted postoperative risk of death derived from the APACHE (Acute Physiology, Age, Chronic Health Evaluation) III score and the preoperative Allproscore. These scores were obtained by merging data from the Australian and New Zealand Intensive Care Society Adult Patient database and Cardiac and Thoracic Surgeons database. An increase in the ARCTIC Index was associated with prolonged cardiopulmonary bypass time and intraoperative blood product transfusions and correlated with procedural morbidity such as reoperation, postoperative renal failure, prolonged ventilation, and stroke.

Coulson and colleagues ${ }^{4}$ should be congratulated for using a unique methodology of integrating 2 large clinical data sets to develop a new concept that may afford the opportunity to evaluate the performance of cardiac surgery programs, with a focus on modifying practice patterns in the operating room to improve outcomes. Two major concerns, however, need to be addressed before routine use of this metric. ${ }^{5}$ The first issue is validity. The ARCTIC index is derived from the Allproscore and the APACHE III scores. The Allproscore is used in Australia and New Zealand but has not been previously tested in other large cohorts or compared with other benchmark risk-assessment models, such as the STSDB. Furthermore, the APACHE III score was not designed and has not been previously used to predict risk of mortality after cardiac surgery. Finally, in this study, data were missing for $29 \%$ of patients undergoing cardiac surgery during the study period. Comparison of 
the matched and unmatched cohorts revealed substantial differences in many variables that are central to risk assessment. The question of validity is clearly manifested by the fact the cardiogenic shock was found to be associated a reduced risk of mortality-negative ARCTIC index score. The second issue is the ease of implementation. Calculation of the ARCTIC index requires data elements that are not routinely collected by cardiac surgery programs. Relying on importing data from external databases or other resources is cumbersome, with inherent potential for errors. Thus the existing data collection tools will have to be modified to include the required elements. The methodology, practicality, and cost associated with this modification must be balanced against the potential added value of a new quality metric.

Despite these limitations, the ARCTIC index is a novel performance measurement metric that may provide patients and all health care stakeholders with a valuable tool to assess quality of care as a step toward identifying and modifying practice patterns, aiming at improved outcomes after cardiac surgery.

\section{References}

1. Beauchamp TL, Childress JF. Principles of biomedical ethics. 6th ed. New York: Oxford University Press; 2009.

2. Shahian DM, Edwards FH, Ferraris VA, Haan CK, Rich JB, Normand SL, et al Quality measurement in adult cardiac surgery: part 1-conceptual framework and measure selection. Ann Thorac Surg. 2007;83(4 Suppl):S3-12.

3. Birkmeyer JD, Dimick JB, Birkmeyer NJ. Measuring quality of surgical care: structure, process, or outcomes? J Am Coll Surg. 2004;198:626-32.

4. Coulson TG, Bailey M, Reid CM, Tran L, Mullany DV, Smith JA, et al. Acute risk change for cardiothoracic admission to intensive care: a new measure of quality in cardiac surgery. J Thorac Cardiovasc Surg. 2014;148:3076-81.

5. Spretus JA, Bonow RO, Chan P, Diamond GA, Drozda JP Jr, Kaul S, et al ACCF/AHA New insights into the methodology of performance measurement: a report of the American College of Cardiology Foundation/American Heart Association Task Force on performance measures. J Am Coll Cardiol. 2010; $56: 1767-82$. 